University of Nebraska - Lincoln

DigitalCommons@University of Nebraska - Lincoln

\title{
Testing the Developmental Nature of Work Motivation Using Kegan's Constructive-Development Theory
}

\author{
Marilyn J. Bugenhagen \\ Marian University, mjbugenhagen@gmail.com \\ John E. Barbuto Jr. \\ University of Nebraska-Lincoln, jbarbuto@fullerton.edu
}

Follow this and additional works at: https://digitalcommons.unl.edu/aglecfacpub

Part of the Other Public Affairs, Public Policy and Public Administration Commons

\begin{abstract}
Bugenhagen, Marilyn J. and Barbuto, John E. Jr., "Testing the Developmental Nature of Work Motivation Using Kegan's Constructive-Development Theory" (2012). Faculty Publications: Agricultural Leadership, Education \& Communication Department. 56.

https://digitalcommons.unl.edu/aglecfacpub/56
\end{abstract}

This Article is brought to you for free and open access by the Agricultural Leadership, Education \& Communication Department at DigitalCommons@University of Nebraska - Lincoln. It has been accepted for inclusion in Faculty Publications: Agricultural Leadership, Education \& Communication Department by an authorized administrator of DigitalCommons@University of Nebraska - Lincoln. 


\title{
Testing the Developmental Nature of Work Motivation Using Kegan's Constructive-Development Theory
}

\author{
Marilyn J. Bugenhagen \\ Marian University, Fond du Lac, WI, USA
}

John E. Barbuto Jr.

University of Nebraska-Lincoln, Lincoln, NE, USA

Corresponding author - Marilyn J. Bugenhagen, Marian University, 45 S. National Avenue, Stayer Center 42, Fond du Lac, WI 54935, USA; email: mjbugenhagen01@marianuniversity.edu

\begin{abstract}
This article reports a field study testing the relationship between individuals' constructive-development level and their sources of work motivation. Constructive development was assessed using the Subject-Object Interview for 53 community and educational leaders. Motivation was assessed using the Motivation Sources Inventory. Results indicated that constructive-development progression was significantly related to instrumental motivation. No other significant relationships were found, indicating that the other four sources of work motivation exist independent of individuals' constructive development. Implications for research and practice are addressed.
\end{abstract}

Keywords: cognition, development, work motivation

\section{Introduction}

The psychological context that precedes contentbased work motivation has received minimal attention in the applied psychology and organizational behavior fields. Considerable research has tested the impact of work motivation (Guzzo, Jette, \& Katzell, 1985; Pritchard, Paquin, DeCuir, McCormick, \& Bly, 2002; Sawyer, Latham, Pritchard, \& Bennett, 1999), and work motivation has been used to understand other behavioral frameworks (Bandura, 1986; Barbuto, Fritz, \& Marx, 2000; Lu, 1999). However, contexts that produce the content of work motivation have been limited to just a few works, which have examined adult development and aging (Kanfer \& Ackerman, 2004), affective experiences (Seo, Barrett, \& Bartunek, 2004), compensation (Kehr, 2004), and self-concept (Leonard, Beauvais, \& Scholl, 1999). There is a need to provide a richer empirical examination of the psychological context of work motivation.

Developmental theorists have described motivation implications of their developmental frameworks that reflect the psychological context for content-based human motivation (youth/adolescents, Loevinger, 1976; Piaget, 1972; and moral development, Kohlberg, 1976). Perhaps the most current thinking is reflected in constructive- development (CD) theory (Kegan, 1982, 1994). Recent work has tested the relationship between personality and CD, labeled as leader development level (Strange \& Kuhnert, 2009), and between leadership performance and CD (Amey, 1991; Bartone, Snook, Forsythe, Lewis, \& Bullis, 2007; Eigel, 1998). Yet most efforts have focused on unit-level performance rather than on understanding the context of work motivation. The linkages between CD theory and content-based work motivation have been assumed in descriptions by CD scholars (Kegan, 1994; Kegan \& Lahey, 1994, 2009). Although these assumptions are intuitively appealing, they have not been subjected to empirical inquiry. Barbuto and Scholl (1998) provided rationale for linkages between CD theory and work motivation, which have not been empirically tested. These assumptions need to be tested prior to any further generalizations regarding $\mathrm{CD}$ and contentbased work motivation. This study tests the role that CD theory plays in work motivation by sampling from a group of community and education leaders.

\section{Work Motivation}

Leonard et al. (1999) proposed a new typology of motivation sources, which was later operationalized with scales to measure the taxonomy (Barbuto \& 
Scholl, 1998). This taxonomy was further developed and tested to predict leaders' behaviors (Barbuto et al., 2000; Barbuto \& Scholl, 1999). In two independent research studies examining antecedents of leaders' behaviors (using these two motivation taxonomies), the five sources of motivation (Barbuto \& Scholl, 1998; Leonard et al., 1999) were better able to predict behavior than McClelland's (1985) three-need model (Barbuto et al., 2000, Barbuto, Fritz, \& Marx, 2002). These five sources of motivation include intrinsic process, instrumental, self-concept external, self-concept internal, and goal internalization.

\section{Five Sources of Work Motivation}

Intrinsic process motivation. If people are motivated to perform certain kinds of work or to engage in certain types of behavior for the sheer fun of it, then intrinsic process motivation is occurring. For this source of motivation, the work itself acts as the incentive because workers enjoy what they are doing. Similar constructs to intrinsic process motivation can be found extensively in the literature. Developmental theorists have described a similar motive using the terms heteronymous morality (Kohlberg, 1976), impulsive (Kegan, 1982; Loevinger, 1976), and, to a lesser extent, preoperational (Piaget, 1972). Other need-based descriptors similar to intrinsic process include early existence needs (Alderfer, 1969), intrinsic pleasure needs (Murray, 1964) and physiological needs (Maslow, 1954). Bandura (1986) describes sensory intrinsic motivation and physiological intrinsic motivation in terms similar to those used to describe intrinsic process motivation. This motive also has been articulated as intrinsic motivation to obtain task pleasure (Deci, 1975) and intrinsic task motivation devoid of external controls or rewards (Staw, 1976).

Past researchers (Deci, 1975; Katz \& Kahn, 1978; Staw, 1976) have used the term intrinsic motivation to represent personal satisfaction derived from achievement of goals or tasks. Intrinsic process motivation is distinct from the classical interpretation of intrinsic motivation because the emphasis with the former is on immediate enjoyment or pleasure during the activity rather than on the satisfaction that results from its achievement. The classic intrinsic motivation is better represented in this motivation taxonomy as self-concept internal.

Instrumental motivation. Instrumental rewards motivate individuals when they perceive their behavior will lead to certain extrinsic tangible outcomes, such as pay, promotions, bonuses, and so on. (Kelman, 1958). This source of motivation integrates Etzioni's (1961) alienative and calculative involvement, Barnard's (1938) exchange theory, and Katz and Kahn's (1978) legal compliance and external rewards. Developmental theorists have described a similar motive as concrete operational (Piaget, 1972), instrumental (Kohlberg, 1976), imperial
(Kegan, 1982), and opportunistic (Loevinger, 1976). Similar instrumental motives have been described by need theorists as a need for power (McClelland, 1961; Murray, 1964), a need for safety (Maslow, 1954), and a need for later existence (Alderfer, 1969).

Instrumental motivation is different from the classic extrinsic or external motivation (Deci, 1975; Katz \& Kahn, 1978; Staw, 1976) in that this motive derives from tangible external rewards, whereas the classic definition includes social rewards and interpersonal exchanges (in this typology, motivation that derives from these rewards is termed self-concept external). Extrinsic motivation is further divided in this meta-theory into two categories of motives: tangible (instrumental) and social (self-concept external). This motivation is characterized by optimizing self-interests but with the recognition that everything or want has its tangible price.

Self-concept external motivation. This source of motivation tends to be externally based when individuals are other directed and seek affirmation of traits, competencies, and values from external perceptions. The ideal self is adopted from the role expectations of reference groups, explaining why individuals high in self-concept external motivation behave in ways that satisfy reference group members, first to gain acceptance and, after achieving that, to gain status.

This source of motivation is similar to Etzioni's (1961) social moral involvement, extrinsic interpersonal motivation described by Deci (1975) and Staw (1976), and Barnard's (1938) social inducements, conformity to group attitudes, and communion. This source of motivation also resembles social identity theory, in which the focus is on establishing and maintaining social reference and standing (Ashforth \& Mael, 1989). Developmental theorists have described a similar motivational stage as interpersonal (Kegan, 1982; Kohlberg, 1976), early formal operational (Piaget, 1972), and conformist (Loevinger, 1976). Other researchers have described similar motivation as a need for affiliation (McClelland, 1961; Murray, 1964); as a need for love, affection, and belonging (Maslow, 1954); and as relatedness needs (Alderfer, 1969). Katz and Kahn (1978) describe employees seeking "membership and seniority in organizations," "approval from leaders," and "approval from groups" in terms similar to those used to describe self-concept external motivation. Classic articulations of social rewards or social exchanges are consistent in concept and motivational explanation with self-concept external motives. Kuhnert and Lewis (1987) propose links between interpersonal motivations and high-order transactions, described here in terms similar to charismatic leadership. Barbuto and Scholl (1999) examined the relationship between work motivation and influence tactics used and found significant correlations between self-concept external motives and social tactics, such as ingratiating and personal appeals. 
Self-concept internal motivation. Self-concept-based motivation will be internal when individuals are inner directed. In this type of motivation, individuals set internal standards for traits, competencies, and values that become the basis for their ideal selves (Leonard et al., 1999). Individuals then engage in behaviors that reinforce these standards and later pursue higher levels of competency.

This source is similar to McClelland's (1961) need for achievement, Deci's (1975) internal motivation to overcome challenges, and Katz and Kahn's (1978) ideal of internalized motivation derived from role performance. Bellah, Madsen, Sullivan, Swidler, and Tipton (1985) describe individualism in terms similar to those used to describe self-concept internal motivation. Developmental theorists have described a similar stage using terms such as full formal operational (Piaget, 1972), social system (Kohlberg, 1976), self-authorship (Kegan, 1982), and conscientious (Loevinger, 1976). Similar motives are described as a need for achievement (McClelland, 1961; Murray, 1964), need for esteem (Maslow, 1954), motivating factors (Herzberg, 1968), and growth needs associated with developing one's potential (Alderfer, 1969).

Bandura (1986) describes self-evaluative mechanisms, self-regulation, and personal standards in terms similar to those used to describe self-concept internal motivation. Katz and Kahn (1978) describe a motive similar to internalized motivation as "self-expression derived from role performance." This motive also has been described as "intrinsic motivation to overcome challenges" (Deci, 1975) and "intrinsic motivation to pursue personal achievement" (Staw, 1976).

Goal internalization motivation. Behavior motivated by goal internalization occurs when individuals adopt attitudes and behaviors congruent with their personal value systems. Strong ideals and beliefs are paramount in this motivational source (Barbuto \& Scholl, 1998). Individuals motivated by goal internalization believe in the cause and have developed a strong sense of duty to work toward the shared goals.

This source of motivation is similar to Kelman's (1958) value system, Katz and Kahn's (1978) internalized values, Deci's (1975) internal valence for outcome, and Etzioni's (1961) pure moral involvement. Each emphasizes a virtuous character and a desire not to compromise these virtues. Bellah et al. (1985) describe habits of the heart in terms similar to goal internalization. Developmental theorists describe a similar motivational stage as postformal operational (Piaget, 1972), principled orientation (Kohlberg, 1976), inter-individual (Kegan, 1982), and autonomous (Loevinger, 1976). Need theorists describe a similar motive as self-actualization (Maslow, 1954).

Goal internalization is different from the previous four sources of motivation because it is clearly marked by the absence of self-interest (Barbuto \& Scholl, 1998). Motivation from this source occurs when individuals believe in the cause. In contrast, intrinsic process mo- tivation requires an enjoyment of the work being performed. Those with high levels of instrumental motivation are driven to perform the work because of an incentive or contingent reward. Individuals with high levels of self-concept external motivation desire to enhance their reputation or image, whereas those with high levels of self-concept internal motivation are stimulated by personal challenge and self-regulation. All these reflect some degree of self-interest; on the other hand, those with high levels of goal internalization motivation are driven solely by a belief that the goals of the organization are both worthwhile and achievable.

\section{Constructive-Development Theory}

CD theory makes two powerful ideas evident: first, the idea that human development evolves qualitatively over time with periods of stability and periods of growth. It has been idealized that constructivism amounts to one's ability to construct reality - the capacity for meaning making (Henderson \& Kegan, 1989). This meaning-making process is understood by how people construct understanding about their experiences. People derive understanding through growth and changes over the course of their life span that signifies the manner in which they develop and organize the complexity of interpersonal relationships (Perry, 1970). Piaget (1972) focused more on how people know rather than on what people know as a means for distinguishing development and cognitive reasoning in children. This conceptual construct was extended into adulthood as a model of development by several prominent scholars (BaxterMagolda, 1992, 1999; Belenky, Clinchy, Goldberger, \& Tarule, 1986; Gilligan, 1982; Kegan, 1982; Kohlberg, 1976; Loevinger, 1976; Perry, 1970).

CD theory postulates an evolution throughout a life span, which informs people's ability to understand their self and their world. Individuals develop from one order to the next with increasing aptitude for sense making of the increasing complexities of life. The constructivist approach illustrates that individuals may construct meaning differently today than they may tomorrow, if they allow experience to inform their understanding (Eigel, 1998). These transitions do not occur in the same manner or with the same timing for all individuals, thus maturation in age does not signal progression in development. The complexity of demands in modern life may place many adults "in over their heads" as they attempt to interact and derive meaning in the complex world around them (Kegan, 1994).

Kegan's theory, first introduced in The Evolving Self (1982), was enhanced through longitudinal research (Kegan, 1994; Kegan \& Lahey, 2009) that outlined five distinct orders of transitional development. In the context of this research, focus was placed on second order through fifth order: second order, the instrumen- 
tal mind; third order, the socialized mind; fourth order, self-authoring mind; and fifth order, self-transforming mind.

First Order-Impulsive: Young children aged 0 to 7 years found in this order are unable to have abstract thought and control their impulses. Their needs are met through others based on their immediate impulses, and they require constant supervision as well as reminders of the rules.

Second Order-Instrumental: Individuals in this order are generally older children aged 7 to 10 years, adolescents, and some adults. Individuals in this order discover that feelings and beliefs exist over time, and they are aware that others have beliefs and feelings that remain constant over time. A rule today is a rule tomorrow; however, there is preoccupation with trying to figure out how to get past the rule if it impedes their way. Empathy is not possible, though individuals know others have feelings and desires. At this order, they are self-centered and see others as helpers or barriers to having their needs met.

Third Order-Socialized (Institutional): This order includes older adolescents (aged 10 years and older) and a majority of the adult population (Kegan, 1994). Individuals in the socialized mind have developed the ability to subordinate their needs to include the needs of others. They have the ability to internalize feelings and emotions of others and are guided by or embedded in the values of the institutions that are important to them (school, religion, political party, etc.). When in conflict between important others, they feel "torn in two" and cannot make decisions easily. Self-esteem is not possible, as there is no "self" outside of those around them. Individuals are socialized by those external to them who define and make up who they are at this order.

Fourth Order-Self-Authoring: This order includes some of the adult population who having achieved the third order and now are self-defined outside of relationships with others and institutions. The previous opinions and desires of others are now internalized and do not hold control over them. Fourth order individuals are able to examine and mediate over these previous value systems and compare them with their own selfgoverning system to make decisions and resolve conflict. Unlike at the third order, self-authoring individuals do not feel "torn" by conflict, because they have their own value system to use in making decisions. Individuals at this level are often characterized as self-motivated, self-directed, and self-monitoring.
Fifth Order-Self-Transforming: Less than $1 \%$ of the adult population achieve the ability to possess their own meaning-making processes and realize that there are faults in even having such a system (Kegan, 1994). These individuals see the similarities rather than the differences between systems. They find value in dichotomy and are content to straddle the gray zone. Their roles are likely to help communities and leaders mediate between the commonalities.

\section{Importance of Transformation Through Order Transitions}

Kegan's CD theory describes the way people grow and change over the course of their adult lives. The theory of involves a transformation to qualitatively different stages of meaning making that is different from learning new information or skills. "New information may add to the things a person knows, but transformation changes the way he or she knows those things" (Berger, Hasegawa, Hammerman, \& Kegan, 2007). This transformation, changes the very form of the meaning-making system-making it more complex, more able to deal with multiple demands and uncertainty (Kegan, 1994). This transformation can be symbolized as the ability to step out of the picture frame and reflect on yourself in that frame and make decisions about your experience in that frame. Kegan (1994) indicates that transformative learning happens when someone changes "not just the way he behaves, not just the way he feels, but the way he knows - not just what he knows, but the way he knows" (p. 17).

\section{Transition Transformation: Moving From Subject to Object}

The growth of the individual is in the transition between the points along the continuum between being fully in one order or another. The transformation of meaning making is a distinction between what Kegan calls that which is subject and which is object. As in the description of standing in the picture frame you are not able to see what is in the picture, the ability to construct meaning in this situation makes us the subject where the experiences are invisible to us. They are the parts of us that are unquestioned and cannot be seen because we hold them internally. We generally cannot name and are unable to reflect on or take a look at the things that we are subject to. Kegan (1994) states "We cannot be responsible for, in control of, or reflect upon that which is subject" (p. 32). Our unquestioned beliefs about the world are held as subject, because we assume those things are obviously true and we do not question these assumptions. Things that are object to us are the opposite of subject. "We have object; we are 
subject" (Kegan, 1994, p. 32). Things that are object are "those elements of our knowing or organizing that we can reflect on, handle, look at, be responsible for, relate to each other, take control of, internalize, assimilate, or otherwise operate upon" (p. 32). Once outside the picture frame, people are able to reflect on their experiences and create meaning and understanding of previously held assumptions.

Kegan's emphasis is with move of elements from subject to object. As transitions allow for us to begin taking increasingly complex elements as object, our world view becomes more complex because we can see and act on more elements. The transition from subject to object, over time, which is different for every individual, means the lenses through which we view the world changes, allowing us to "see" it differently. Kegan's five orders demonstrate qualitatively different ways of constructing reality, and these shifts result in a more complex view from the previous order. No one order is better than any other, just more complex, and no one order is more valuable than any other. People can be ethical or unethical, generous or stingy, just or unjust at any of the orders. Berger et al. (2007) wrote the following:

The key reason for understanding this journey is not to examine the self-complexity of individuals for the sake of labeling them or putting them into a restrictive box, but to be able to see the ways that the experiences people have might be more supportive of their current meaning-making system and also of their growth. (p. 3)

Using this theory to understand motivation, leadership, and other behaviors may allow us to examine the fit between leader's capacities and the demands put on them for complex thinking and leading. Kegan (1994) asserts that when we do not have the capacity to meet the demands in our lives, we may feel unhappy, undervalued, and "in over their heads."

Although recent research has used CD order, there has been a tendency to define a "static" level of the order, which Kegan and Lahey (2009) define as a plateau in adult mental development for complexity. Our development occurs in periods of stability and change for a considerable time period, with the time on the plateau getting longer and longer with fewer people reaching the fourth and fifth orders. Thus, capturing the transitions between the plateaus could be more important than the actual achievement of a plateau itself.

\section{Linking Constructive-Development Order to Work Motivation}

Kuhnert and Lewis (1987) suggested that theories of leadership development might be extended by using $\mathrm{CD}$ theory to explain the differences in the way a lead- er develops his leadership style. McCauley, Drath, Palus, O'Connor, and Baker, (2006) asserted that to have a

greater impact on the leadership field, constructive developmental theory needs to generate more robust research, to link more clearly with on-going streams of leadership research, and to explore the contribution of aspects of the theory beyond individual order of development." (p. 634)

Research has found relationships in the transitions between the third and fourth Orders (3[4], 3/4, 4/3, 4[3]) and transformational leadership behaviors (Amey, 1991; Benay, 1997), leader effectiveness (Eigel, 1998), and personality (Strange \& Kuhnert, 2009). The reported sample sizes from these studies were 5, 8, 42, and 67, respectively.

To date no studies have examined CD order with work motivation. Although intuitively it may be reasonable that the five sources of work motivation would act consistently with the levels of $\mathrm{CD}$-where stage progression in $\mathrm{CD}$ would lead to progression to latter sources of work motivation (e.g., self-concept internal and goal internalization) - without any prior research to draw from, such hypotheses would be based entirely on conjecture. Barbuto and Scholl (1998) integrated many developmental theories with the metatheory of work motivation and aligned instrumental CD second order with self-concept motivation, interpersonal/ institutional CD third order with self-concept external motivation, self-authoring $C D$ fourth order with selfconcept internal motivation, and self-transforming CD fifth order with goal internationalization motivation. If the CD orders and sources of work motivation do line up, it is expected that they would follow this pattern (Hypothesis 1).

A counter expectation would be that sources of work motivation might act and exist independent of CD levels, whereby any of the five sources of work motivation could exist at all levels of development. This would be consistent with recent findings that reported other person-centered variables as distinct from CD (Strange \& Kuhnert, 2009). Although this would be counter to most CD theorists' views (Kegan, 1982, 1994; Kegan \& Lahey, 2009), it would be consistent with the writings on work motivation (Barbuto, Fritz, \& Marx, 2000; Barbuto \& Scholl, 1998, Leonard et al., 1999). Although this article does not test a series of hypotheses, it tests two competing views: one that work motivation will behave consistently with CD (Hypothesis 1) and the other that work motivation will exist independently of CD (Hypothesis 2). This study actually tests Hypothesis 1 against $\mathrm{Hy}-$ pothesis 2 .

Hypothesis 1: Constructive-development order positively relates to sources of work motivation, 
where progression in constructive-development order will accompany progressive sources of work motivation (intrinsic process to instrumental to self-concept external to self-concept internal to goal internalization).

Hypothesis 2: Sources of work motivation will exist independently of constructive-development order, where sources of work motivation may exist in varying proportions across all levels of constructive-development.

\section{Method}

The research framework was tested using a mixedmethod design sampling community leaders in training settings across the United States. The data collected consisted of leaders' self-reported motivational sources and researcher-facilitated subject-object interviews. The assessment was administered using a web-based survey, whereas interviews were conducted via telephone.

\section{Participants}

The sample of leaders consisted of $57 \%$ female participants and averaged 33 years of age. Twenty percent identified as non-White, whereas $80 \%$ reported their race as White, Caucasian (non-Hispanic). Participants were recruited nationally through two leadership development programs: three community based and one educational cohort based. Sixty-one percent of the population had advanced degrees, 9\% had bachelor's degrees, and 30\% were students earning their bachelor's degrees.

\section{Measures}

Motivation Sources Inventory. Leaders' sources of motivation were measured using the Motivation Sources Inventory (MSI; Barbuto, 2004). The inventory contains 30 items, 6 for each subscale, measured on 6-point Likerttype scale. Scores were obtained by parceling responses for each subscale. Sample items and coefficient alphas for the five sources included the following: intrinsic process ("I would prefer to do things that are fun," $a=.71$ ), instrumental ("I like to be rewarded when I take on additional responsibilities," $a=.78$ ), self-concept external ("It is important to me that others appreciate the work I do," $\alpha=.85$ ), self-concept internal ("Decisions I make reflect standards I've set for myself," $\alpha=.82$ ), and goal internalization ("I work hard for a company if I agree with its mission," $a=.73$ ).

Subject-Object Interview. CD order was determined through use of the Subject-Object Interview (SOI; Lahey, Souvaine, Kegan, Goodman, \& Felix, 1988). The $\mathrm{SOI}$ is designed to assess for understanding what the participant's experiences mean to them and to classify their developmental order using CD theory (Lahey et al., 1988). In analysis, the researcher attempts to understand how study participants make meaning of their experiences and to distinguish the participants at particular transition points in the orders.

\section{Procedures}

Participants were recruited for this study through their involvement in four leadership development training programs. Participants were given the choice to participate or not participate in the study without any repercussions. Participation in the study was not a condition of participation in the training activities. Procedures were closely monitored and approved through the institutional review board for research compliance at the second author's university. Participants completed the MSI on a web-based system. Interviews were conducted via telephone using a conference call system to record the interviews as mp3 files. Interviews were transcribed and checked against the mp3 file.

SOIs were conducted over the telephone and digitally recorded. All participants were provided with a written protocol introducing them to the interview process and prompting them to reflect on particular words and phrases. For example, participants were provided with the following statement related to ANGRY:

If you were to think back over the last several weeks, even a couple of months, and you think about times you felt really angry about something, or times you got really mad or felt a sense of outrage or violation; are there two or three things that come to mind? Take a minute to think about it, if you like, and jot down on the card whatever you need to remind you of what they were. (If nothing comes to mind for the interviewee for this particular word, move to the next card.) (Lahey et al., 1988, p. 428-429)

During the interview, the interviewer engaged in combined empathic listening and probing for deeper understanding of how the participants construct and understand their experiences. As participants spoke about "angry," the interviewer probed the responses searching for not what the participants were angry about but the how and why behind the participants' experience of being angry. The interviewer simultaneously formed and tested hypotheses on the participants' place in the orders. To find the order achieved by the participant, the interviewer tested the bottom of the transition points and "pushed" for the highest constructed order of meaning making. There are 21 possible distinctions across all orders in this construct; however, in this study, only second to fifth Order were tested because of participant age range. This provided a range across 16 transition places. "Pushing" or testing toward the higher order revealed the participant's ability for higher complexity thinking. The interviewer was trained by members of Kegan's research group in the 
method, had piloted several interviews prior to the actual research interviews, and was coached by members of the research group. The key to the interview was to obtain participant responses that allowed the researcher to focus in on the predominate transitional order.

There are 21 possible placements within the five orders of CD with five hallmarks (1-5; Kegan, 1982; Lahey et al., 1988).

\begin{tabular}{|c|c|c|}
\hline First Order: & $\begin{array}{l}1,1(2), 1 / 2 \\
2 / 1,2(1)\end{array}$ & Impulsive \\
\hline Second Order: & $\begin{array}{l}2,2(3), 2 / 3 \\
3 / 2,3(2)\end{array}$ & Instrumental \\
\hline Third Order: & $\begin{array}{l}3,3(4), 3 / 4 \\
4 / 3,4(3)\end{array}$ & $\begin{array}{l}\text { Socialized } \\
\text { (dependent/ } \\
\text { institutional) }\end{array}$ \\
\hline Fourth Order: & $\begin{array}{l}4,4(5), 4 / 5 \\
5 / 4,5(4)\end{array}$ & $\begin{array}{l}\text { Self-authoring } \\
\text { (independent) }\end{array}$ \\
\hline Fifth Order: & 5 & $\begin{array}{l}\text { Self-transforming } \\
\text { (interindependent) }\end{array}$ \\
\hline
\end{tabular}

The transitions between the orders signifies the emergence of the next order, 2(3 emerging); the presence of both orders in balance with the first dominating, $2 / 3$ or $3 / 2$; and the next order dominating with the previous order fading, 3 (2 fading). These transitions represent the movement in thinking from subject to object and an increase in the complexity of understanding and meaning making. At times the orders are vying for dominance, which can be seen in people who seem to waver and appear indecisive in the ways they know and understand the world. The previous order that was subject can be now reflected on as object where the new way of knowing allows people to make meaning of the world through the lens of the new order.

\section{Data Analysis}

Data from the MSI were downloaded into SPSS for analysis. Subscale formulas were created in preparation for statistical analysis with scores from the SOI.

Transcriptions of the SOIs were interpreted by the lead author identifying phrases (or "bits") revealing meaning-making structure. Each "bit" was assigned a transition score amongst the 16 possible points in $\mathrm{CD}$ orders assessed in this study. A hypothesis of the highest transition point was assigned if three or more "bits" demonstrated meaning making at that specific order. Two secondary raters scored random interview transcriptions at a ratio of 1 to 3 for purposes of interrater reliability. The researcher and second rater's overall interview scores must be within one transition position, 1/5, for reliability. If their scores did not agree, a review of the transcript and comparisons were made to determine the final score. Dissertations and research using this interrater reliability technique report complete agreement reliabilities of $70 \%$ to $80 \%$ range and most reliabilities at $100 \%$ for a $1 / 5$ order discrimination (Lahey et al., 1988).
The SOI transcripts achieved overall interrater reliability of .83 , within the accepted test-retest reliability range of .75 to .90 . The research method supports a test of $20 \%$ of the interviews by a second rater, with either complete agreement or agreement within $1 / 5$ stage as acceptable reliability. The general preference for interrater reliability through much of the research supports the range method and is supported by a measure with the longest "track record," namely, the moral judgment interview (Colby \& Kohlberg, 1987). The moral judgment interview at the finest differentiation supports 13 distinctions between Stages 1 and 5; it distinguishes two transition points between any two stages. The SOI makes an even finer distinction between any two orders with 21 distinctions between Orders 1 to 5 and distinguishes four transitional points between any two orders. This research achieved 10 interview scores within the acceptable $1 / 5$ distinction, 5 scores with 100\% agreement, and 3 scores not in agreement with the 18 interviews scored by two raters.

Each transcription was given two scores including the actual transition order using a formulation sheet and a converted score for use in the statistical analysis with the MSI. These scores were 2, 2.2, 2.4, 2.6, and 2.8 (within the second order transition), with an overall range of Orders 2 to 5 as obtained from the analysis of the SOI transcripts.

\section{Results}

The MSI subscales performed above the .70 of Cronbach's alpha with an overall .89. The SOI scale was assessed for interrater reliability overall at .83, with an accepted test- retest reliability range of .75 to .90 . The scores for CD order from this study compare favorably with the distribution between orders for comparison studies (see Table 1). Fourth order had a smaller sample, which could be explained by the $M=33$ years of age for this study's participants. There were no participants in this sample $(N=53)$ who had progressed to the fifth order, which could be explained both by the relatively young age of the group and by the rarity with which this order presents in the general population. Kegan (1994) estimates that less than $1 \%$ of the general population presents in fifth order in CD evaluations. This study included a higher percentage of participants in the 18 to 26 years of age category as compared with other studies. Second to third order scores were a higher percentage in the sample, explained in part by the larger proportion $(39 \%)$ of 18 - to 26 -year-old participants in this study.

The leaders' CD order was tested as predictor of leaders' sources of work motivation. Simple statistics and correlations were calculated for all variables of the study (leaders $N=53$; see Table 2). Four of the five sources of work motivation indicated no significant relationship with $\mathrm{CD}$. CD order was positively related to instrumental work motivation $(r=.35)$, which does not 
Table 1. Constructive-Development Order Distribution and Comparison Studies

\begin{tabular}{|c|c|c|c|c|c|}
\hline Orders Scores & \multicolumn{5}{|c|}{$n(\%)$} \\
\hline 5 & $0(0)$ & $0(0)$ & $0(0)$ & $0(0)$ & $0(0)$ \\
\hline $4-5$ & $4(8)$ & $5(12)$ & $6(10)$ & $15(7)$ & $17(6)$ \\
\hline 4 & $8(15)$ & $27(64)$ & $25(42)$ & $83(40)$ & $9(34)$ \\
\hline 3 & $7(13)$ & $2(5)$ & $7(11)$ & $31(15)$ & $40(14)$ \\
\hline $2-3$ & $13(25)$ & $1(2)$ & $0(0)$ & $5(2.5)$ & $22(8)$ \\
\hline 2 & $1(1)$ & $0(0)$ & $0(0)$ & $5(2.5)$ & $15(5)$ \\
\hline
\end{tabular}

a. From Eigel (1998).

b. From Kegan (1994).

Table 2. Simple Statistics and Correlation Matrix ${ }^{a}$

\begin{tabular}{lrlllllll}
\hline \multicolumn{2}{l}{ Variable Mean } & SD & CD & IP & IM & SCE & SCI & GI \\
\hline 1. CD & 3.26 & 0.63 & .84 & & & & & \\
2. IP & 14.42 & 5.82 & .22 & .85 & & & & \\
3. IM & 16.28 & 5.56 & $.35^{\star}$ & $.33^{*}$ & .82 & & & \\
4. SCE & 14.47 & 5.97 & .20 & $.69^{\star *}$ & $.48^{\star *}$ & .90 & & \\
5. SCI & 12.43 & 6.12 & .05 & $.78^{\star *}$ & $.32^{\star}$ & $.69^{\star *}$ & .93 & \\
6. GI & 11.72 & 7.13 & .05 & $.84^{\star *}$ & $.27^{\star}$ & $.65^{\star *}$ & $.96^{\star *}$ & .95
\end{tabular}

$\mathrm{CD}=$ Constructive-development order; IP = intrinsic process; $\mathrm{IM}=$ instrumental motivation; $\mathrm{SCE}=$ self-concept external; $\mathrm{SCI}=$ self-concept internal; GI = goal internalization. Scale reliabilities on the diagonal. Motivation Sources Inventory Scale: 0 = entirely disagree, $5=$ entirely agree. CD Scale: 2.0-5.0.

a. Motivation Sources Inventory Subscales and Constructive-Development $\operatorname{Order}(N=53)$.

${ }^{*} p<.05$, two-tailed; ${ }^{* *} p<.01$, two-tailed.

support Hypothesis 1. There were no other relationships to report, which collectively supports Hypothesis 2.

\section{Discussion}

The results of this study provide a view of study participants' sources of work motivation and level of $\mathrm{CD}$ order. This project tested the developmental nature of work motivation by examining cognitive developmental stage progression with self-reported sources of work motivation. The relationship between CD and instrumental motivation indicates that development (grows and changes across the life space) is generally accompanied by increased motivation derived from tangible rewards. As individuals increase their developmental orders, they become more driven by tangible and tacit rewards aligned with personal and organizational values.

When individuals transition through the $\mathrm{CD}$ orders, they become more deeply engaged in the meaning and purpose of the organization or cause. This deeper lev- el of complex thinking likely merits an emphasis on the financial reward aspects of work. Although individuals can access all sources of motivation for work, it appears that as they transition from one order to the next, their levels of instrumental motivation increases and the sources of these tangible rewards may shift to reflect revised values that emerged from stage progression. In some ways, transitions in CD order seem to instigate increased attention and motivation derived from instrumental sources. A reviewer questioned whether this increase in work motivation would be sustainable or short-lived. A longitudinal design would allow for testing this possibility, where sources of work motivation and $C D$ order would be retested 6 months or 1 year later to test for work motivation change.

This counters prior studies that would have expected other sources of work motivation to be more prevalent; these findings are consistent with the integrative taxonomy of motivation (Leonard et al., 1999) and articulated in an integration of many work motivation theories (Barbuto \& Scholl, 1998). This integrative taxonomy performed as expected by original conceptualizations and by subsequent work that described the sources of work motivation as being prevalent across all contexts, where all five sources exist at all points in life (Barbuto et al., 2000).

Locke, Feren, McCaleb, Shaw, and Denny (1980) carried out a meta-analysis and concluded that money is the most instrumental incentive. In moving through the developmental levels, the individual is either in a process of forming a self connected closely to the organization and the people around them or is in a process of forming one's own value system allowing him or her to differentiate self from others (Kegan, 1982). This process although evolutionary can put leaders in a place where the world around them is holding them at a level, whereas they are attempting to transition forward. Motivation for this type of evolution could be interpreted as instrumental, as the rewards of evolving to another order of CD come from choices that are not valued in the previous order. 
The limitations of this study included the broad sample of participants with a wide educational attainment background (enrolled in postsecondary education to holding a terminal degree), wide age range (18-55 years), and leader involvement in a broad range of organization and workplace environments. A focused study of particular leaders in one demographic might yield different outcomes. For example, a study of leaders 40 years of age and older might find a more advanced CD order overall.

Implications surrounding the outcomes of this study have both practical and future research implications. As we move into more complex environments, where employers expect more complexity of thinking, systems of compensation (instrumental motivation) will need to align with the performance abilities of the employee. The ability of individuals to hold multiple perspectives, including their own, in the balance for decision making and organizational goals will put most people interested in leadership positions "in over their heads" (Kegan, 1994). How a person's leadership is perceived by those who follow is a function of both the meaning systems of the followers and the meaning system of the leader. According to Berger (1999), "followers ... are generally dissatisfied with leaders who are operating out of a meaning system less developed than their own." What a follower experiences as motivational support from a leader will differ depending on the follower's developmental position. Leaders who can provide support in forms the followers themselves experience as support will be more effective.

Although most views motivational sources are related to intrinsic and extrinsic motivation, this simple taxonomy does not have enough complexity for the world. The taxonomy of multiple sources of motivation connects well with the development of individuals through life. The motivation for work sources may become more advanced in transitions to upper levels of CD orders. This may have implications for compensation systems in providing instrumental incentives or inducements for more complex leadership positions.

The implications for leader development interventions and training are numerous. Human resource recruiting might be affected, because $\mathrm{CD}$ order does not appear to precede the sources of motivation in a hierarchical way. None of the five sources can be described as higher or better than the others - which is counter to some of the basic tenants of CD theory, which advocates stage progression. There is no conclusion from this study regarding CD's impact on work motivation or organizational performance.

If $\mathrm{CD}$ order does not precede motivation, the next question that needs to be examined is whether it precedes any other person-centered variable. One recent study did not find conclusive evidence that personality connects to leader development level (CD order;
Strange \& Kuhnert, 2009). This study found only one connection, instrumental motivation, which is counterintuitive to the beliefs about motivation and life span development: Most would have casually assumed that instrumental motivation would decrease during the life span. This indicates that a strong priority needs to be placed on testing other person-centered variables with CD theory.

Future research may test other salient organizational behavior and applied psychology constructs with CD to ascertain their developmental nature. The process of researching CD theory is a challenging one because of the time requirement for each point of data ( 1 hour interview, 2-4 hours of transcribing, 2-3 hours scoring), making studies with more appropriately large samples difficult to design. However, the difficulty of this type of research design does not change the necessity for its occurrence. Researchers are encouraged to collaborate to generate larger sample projects to test $\mathrm{CD}$ simultaneously with multiple constructs in the field in order to optimize the time intensity that $\mathrm{CD}$ data collection entails. Future research may also link CD theory with leadership constructs such as transformational, authentic, or servant leadership.

\section{References}

Alderfer, C. P. (1969). An empirical test of a new theory of human needs. Organizational Behavior and Human Performance, 4, 142-175.

Amey, M. J. (1991). Constructive/development theory and leadership: A question of perceived leadership. Chicago, IL: American Educational Research Association.

Ashforth, B., \& Mael, F. (1989). Social identity theory and the organization. Academy of Management Review, 14, 20-39.

Bandura, A. (1986). Social foundations of thought and action: A social cognitive theory. Englewood Cliffs, NJ: Prentice Hall.

Barbuto, J. E. (2004). The Motivation Sources Inventory. Lincoln, NE: Future Leadership.

Barbuto, J. E., Fritz, S. M., \& Marx, D. (2000). A field study of two measures of work motivation for predicting leader's transformational behaviors. Psychological Reports, 86(1), 295-300.

Barbuto, J. E., Fritz, S. M., \& Marx, D. (2002). A field study examining two measures of work motivation for predicting leaders' influence tactics used. Journal of Social Psychology, 142, 601-616.

Barbuto, J. E., \& Scholl, R. W. (1998). Motivation Sources Inventory: Development and validation of new scales to measure an integrative taxonomy of motivation. Psychological Reports, 82, 1011-1022.

Barbuto, J. E., \& Scholl, R. W. (1999). Leaders' sources of motivation and perceptions of followers' motivation as predictors of leaders' influence tactics used. Psychological Reports, 84, 1087-1098. 
Barnard, C. (1938). The functions of the executive. Cambridge, MA: Harvard University Press.

Bartone, P., Snook, S., Forsythe, G., Lewis, P., \& Bullis, R. (2007). Psychosocial development and leader performance of military officer cadets. Leadership Quarterly, 18(5), 490-504.

Bar-Yam, M. (1991). Do women and men speak in different voices? A comparative study of self-evolvement. International Journal of Aging \& Human Development, 32, 247-259.

Baxter-Magolda, M. (1992). Knowing and reasoning in college. San Francisco, CA: Jossey-Bass Publishers.

Baxter-Magolda, M. (1999). Creating contexts for learning and self-authorship: Constructive development pedagogy. Nashville, TN: Vanderbilt University Press.

Belenky, M. F., Clinchy, B. M., Goldberger, N. R., \& Tarule, J. M. (1986). Women's ways of knowing: The development of self, voice and mind. New York, NY: Basic Books.

Bellah, R. N., Madsen, R., Sullivan, W. M., Swidler, A., \& Tipton, S. M. (1985). Habits of the heart: Individualism and commitment in American life. Berkeley: University of California Press.

Benay, P. (1997). Social cognitive development and transformational leadership: A case study (Unpublished doctoral dissertation). University of Massachusetts, Amherst.

Berger, J. G. (1999). Key concepts for understanding the work of Robert Kegan. Retrieved from http://garveyberger.com/ writing_files/Berger $\% 20$ Kegan $\% 20$ key $\% 20$ concepts $\% 20$ 2010.pdf

Berger, J. G., Hasegawa, B., Hammerman, J., \& Kegan, R. (2007). How consciousness develops adequate complexity to deal with a complex world: The subject-object theory of Robert Kegan. Retrieved from http://terrypatten.typepad.com/iran/ files/KeganEnglish.pdf

Colby, A., \& Kohlberg, L. (1987). Measurement of moral judgments: Standard issue scoring manual (Vol. 2). Cambridge, England: Cambridge University Press.

Deci, E. L. (1975). Intrinsic motivation. New York, NY: Plenum Press.

Eigel, K. M. (1998). Leader effectiveness: A constructive developmental view and investigation (Unpublished doctoral dissertation). University of Georgia, Athens.

Etzioni, A. (1961). A comparative analysis of complex organizations. Glencoe, IL: Free Press.

Gilligan, C. (1982). In a different voice. Cambridge, MA: Harvard University Press.

Guzzo, R., Jette, R., \& Katzell, R. (1985). The effects of psychologically based intervention programs on worker productivity: A meta-analysis. Personnel Psychology, 38, 275-291.

Henderson, A. F., \& Kegan, R. (1989). Learning, knowing, and the self: A constructive-development view. In K. Field, B. J. Cohler, \& G. Wool (Eds.), Learning and education: Psychoanalytic perspectives (pp. 267-303). Madison, CT: International Universities Press.
Herzberg, F. W. (1968). One more time, how do you motivate employees? Harvard Business Review, 46(1), 53-62.

Kanfer, R., \& Ackerman, P. (2004). Aging, adult development, and work motivation. Academy of Management Review, 29 (3), 440-458.

Katz, D., \& Kahn, R. L. (1978). The social psychology of organizations. New York, NY: Wiley.

Kegan, R. (1982). The evolving self: Problem and process in human development. Cambridge, MA: Harvard University Press.

Kegan, R. (1994). In over our heads: The mental demands of modern life. Cambridge, MA: Harvard University Press.

Kegan, R., \& Lahey, L. L. (1994). Adult leadership and adult development: A constructivist view. In B. Kellerman (Ed.), Leadership: Multidisciplinary perspectives (pp. 200-230). Englewood Cliffs, NJ: Prentice Hall.

Kegan, R., \& Lahey, L. (2009). Immunity to change: How to overcome it and unlock the potential in yourself and your organization. Boston, MA: Harvard Business School Press.

Kehr, H. (2004). Integrating implicit motives, explicit motives, and perceived abilities: the compensatory model of work motivation and volition. Academy of Management Review, 29, 479-499.

Kelman, H. C. (1958). Compliance, identification, and internalization: Three processes of attitude change. Journal of Conflict Resolution, 2, 51-56.

Kohlberg, L. (1976). Collected papers on moral development and moral education. Cambridge, MA: Center for Moral Education.

Kuhnert, K. W., \& Lewis, P. (1987). Transactional and transformational leadership: A constructive/developmental analysis. Academy of Management Review, 12, 648-658.

Lahey, L. L., Souvaine, E., Kegan, R., Goodman, R., \& Felix, S. (1988). A guide to the subject-object interview: Its administration and interpretation. Cambridge, MA: Harvard University Graduate School of Education.

Leonard, N. H., Beauvais, L. L., \& Scholl, R. W. (1999). Work motivation: The incorporation of self concept-based processes. Human Relations, 52, 969-998.

Locke, E. A., Feren, D. B., McCaleb, V. M., Shaw, K. N., \& Denny, A. T. (1980). The relative effectiveness of four methods of motivating employee performance. In K. Duncan, M. Gruneberg, \& D. Wallis (Eds.), Changes in working life (pp. 363-388). New York, NY: Wiley.

Loevinger, J. (1976). Ego development. San Francisco, CA. Jossey-Bass.

$\mathrm{Lu}, \mathrm{L}$. (1999). Work motivation, job stress and employees' wellbeing. Journal of Applied Management Studies, 8(1), 61-72.

Maslow, A. (1954). Motivation and personality. New York, NY: Harper \& Row.

McCauley, C. D., Drath, W. J., Palus, C. J., O'Connor, P. M. G., \& Baker, B. A. (2006). The use of constructive developmental theory to advance the understanding of leadership. The Leadership Quarterly, 17, 634-653. 
McClelland, D. C. (1961). The achieving society. Princeton, NJ: Van Nostrand

McClelland, D. C. (1985). Human motivation. Glenview, IL: Scott, Foresman \& Co. Murray, E. J. (1964). Motivation and emotion. Englewood Cliffs, NJ: Prentice Hall.

Perry, W. (1970). Forms of intellectual and ethical development in college years: A scheme. New York, NY: Hold, Reinhart \& Winston.

Piaget, J. (1972).Intellectual evolution from adolescence to adulthood. Human Development, 15, 1-12.

Pritchard, R. D., Paquin, A. R., DeCuir, A. D., McCormick, M. J., \& Bly, P. R. (2002). Measuring and improving organizational productivity: An overview of ProMes, the productivity measure and enhancement system. In R. D. Pritchard, H. Holling, F. Lammers, \& B. D. Clark (Eds.), Improving organizational performance with the productivity measurement and enhancement system: An international collaboration (pp. 3-50). Huntington, NY: Nova Science.

Sawyer, J. E., Latham, W. R., Pritchard, R. D., \& Bennett, W. R. (1999). Analysis of work group productivity in an applied setting: Application of a time series panel design. Personnel Psychology, 52, 927-967.

Seo, M., Barrett, L., \& Bartunek, J. (2004). The role of affective experience in work motivation. Academy of Management Review, 29, 423-439.

Staw, B. M. (1976). Intrinsic and extrinsic motivation. Morristown, NJ: Silver Burdett.

Strange, S. E., \& Kuhnert, K. W. (2009). Personality and leadership development levels as predictors of leader performance. The Leadership Quarterly, 20, 421-433.

\section{The Authors}

Marilyn J. Bugenhagen is assistant professor of leadership studies at Marian University, Wisconsin and has been researching leadership and constructive-development since 2004. Her research interests include leadership education, leadership spirituality, constructive-development, and antecedents of leadership.

John E. Barbuto Jr. is associate professor of leadership studies at the University of Nebraska-Lincoln. He earned his $\mathrm{PhD}$ from the University of Rhode Island. His research interests include self-concept based models of work motivation, servant leadership, antecedents of leadership, global leadership, and pedagogical methods. 